\title{
Evaluation of gene expression profiling in a mouse model of L-gulonolactone oxidase gene deficiency
}

\author{
Jian Yan ${ }^{1}$, Yan Jiao ${ }^{2}$, Xinmin $\mathrm{Li}^{3}$, Feng Jiao ${ }^{2}$, Wesley G. Beamer ${ }^{4}$, Cliff J. Rosen ${ }^{4}$ and Weikuan $\mathrm{Gu}^{2}$ \\ ${ }^{1}$ Department of Biology, University of Memphis, Memphis, TN, USA. \\ ${ }^{2}$ Center of Genomics and Bioinformatics \& Center of Diseases of Connective Tissues, Department of \\ Orthopedic Surgery-Campbell Clinic, University of Tennessee Health Science Center, Memphis, TN, USA. \\ ${ }^{3}$ Functional Genomics Facility, University of Chicago, Chicago, IL, USA. \\ ${ }^{4}$ The Jackson Laboratory, Bar Harbor, ME, USA.
}

\begin{abstract}
Humans and guinea pigs are species which are unable to synthesize ascorbic acid (vitamin C) because, unlike rodents, they lack the enzyme L-gulonolactone oxidase (Gulo). Although the phenotype of lacking vitamin $\mathrm{C}$ in humans, named scurvy, has long been well known, information on the impact of lacking Gulo on the gene expression profiles of different tissues is still missing. This knowledge could improve our understanding of molecular pathways in which Gulo may be involved. Recently, we discovered a deletion that includes all 12 exons in the gene for Gulo in the sfx mouse, characterized by spontaneous bone fractures. We report here the initial analysis of the impact of the Gulo gene deletion on the murine gene expression profiles in the liver, femur and kidney.
\end{abstract}

Key words: spontaneous fracture, bone, gene expression, L-gulonolactone oxidase, vitamin C.

Received: January 10, 2006; Accepted: November 22, 2006.

\section{Introduction}

In humans, the lack of vitamin $\mathrm{C}$ (L-ascorbic acid) causes scurvy, a disease characterized by spongy gums, loosening teeth, and bleeding into the skin and mucous membranes. Humans and guinea pigs have to obtain vitamin C from food, because they are unable to synthesize ascorbic acid, due to the absence of the gene that encodes L-gulonolactone oxidase (Gulo). There are numerous studies on scurvy using different animal models that show a wide range of bone and skeletal abnormalities associated with the lack of Gulo. However, spontaneous bone fracture has not been reported as a major defect caused by ascorbic acid deficiency.

The spontaneous bone fracture $(s f x)$ mouse is a mouse model for stage-specific bone growth failure and fracture. Initial studies show that $s f x$ mice have reduced bone mass, abnormalities of bone architecture and a predisposition to fracture spontaneously at a young age (Beamer et al., 2000). Heterozygous $\left(s f x^{-} /+\right)$mice are indistinguishable from homozygous $(+/+)$ wild-type mice at all ages. Mice

Send correspondence to W. GU. Center of Genomics and Bioinformatics \& Center of Diseases of Connective Tissues, Department of Orthopedic Surgery-Campbell Clinic, University of Tennessee Health Science Center, 956 Court Ave, Memphis, TN, USA. E-mail: wgu@utmem.edu. which are homozygous for the $s f x$ locus appear phenotypically normal until the end of weaning at 21 days of age. By 49-56 days of age, the mutants show radiographic evidence of compressional fractures of the distal femur and other skeletal sites such as the vertebrae. Histologically, bone sections from the axial and appendicular skeleton show decreased bone formation (with virtually no osteoid present) and decreased basophilia in the osteoblasts.

Using an integrated strategy that combines classical positional cloning and genome resource mapping, we have identified on chromosome 14 of the $s f x$ mouse a deletion of approximately $38 \mathrm{~kb}$ of genomic DNA that includes the entire Gulo gene. Further studies showed that this deletion is responsible for the disease phenotypes in bone as well as in other tissues in the $s f x$ mouse (Beamer et al., 2000; Jiao et al., 2005), suggesting that it has a wide pathological impact on different organs of the mouse.

In order to examine the molecular effects of the Gulo deletion in $s f x$ mice, we conducted a preliminary study on the gene expression profile of $s f x$ mice using cDNA microarray. Our data show significantly altered gene expression profiles in the femur, kidney and liver. Different gene expression patterns in each of those tissues suggest that Gulo performs a variety of biological functions in different tissues. 


\section{Materials and Methods}

\section{Animals}

Wild-type $+/+$ BALB/cBy and heterozygous $s f x /+$ mice were obtained from The Jackson Laboratory. The homozygous $s f x / s f x$ mice were produced at the University of Tennessee Health Science Center (UTHSC) by intercrossing heterozygous $s f x /+$ mice. Mice were housed at the animal research facility, Coleman Building, UTHSC, Memphis, TN, under the conditions of $14 \mathrm{~h}$ light $/ 10 \mathrm{~h}$ darkness, ambient temperature of $20 \pm 2{ }^{\circ} \mathrm{C}$, and relative humidity of $30-60 \%$. Experimental procedures for this study were approved by the IACUC of the UTHSC. For microarray analysis, three age-matched, wild-type $+/+$ BALB/cBy, inbred strain mice (WT group; 2 males, 1 female) and 3 homozygous $s f x / s f x$ mice (SFX group; 2 males, 1 female) were used. They were handled as previously described (Jiao et al., 2005). At the age of 6 weeks, they were sacrificed, and femur, liver and kidney specimens were immediately taken out and preserved in liquid nitrogen. For RT-PCR, another panel of age- and sex-matched wild-type and $s f x / s f x$ mice ( 2 females and 2 males) was used and handled in the same way.

\section{Total RNA extraction}

Total RNAs were extracted from various tissues using Trizol Reagent (Life Technologies Inc.) (Gu et al., 2002a), and the quality of the resultant total RNA was determined by observing distinct $28 \mathrm{~S}$ and $18 \mathrm{~S}$ ribosomal bands on (a) formaldehyde-agarose gel. The yield and purity of the extracted RNA were quantified by spectrophotometry using an Eppendorf Biophotometer. Samples with a $28 \mathrm{~S} / 18 \mathrm{~S}$ ratio of $\geq 1.8$ and an A260/A280 ratio of 1.8-2.1 were chosen for this study.

\section{Microarray analysis}

Total RNAs were isolated from wild-type +/+ and the $s f x$ mouse tissues (femur, liver, and kidney). Individual RNA samples in each group were pooled before use. Eight $\mu \mathrm{g}$ of total RNA for each group were used for cDNA synthesis by the SuperScript Choice System (Invitrogen, CA), followed by cRNA synthesis using an Enzo ${ }^{\circledR}$ BioArray HighYield RNA transcript labeling kit. Generated cRNA was hybridized to a GeneChip mouse genome U74Av2 array (Affymetrix, CA) representing $\sim 12,000$ mouse transcripts, at $45^{\circ} \mathrm{C}$ for $16 \mathrm{~h}$, as recommended by the manufacturer. The arrays were washed and stained in the Affymetrix Fluidics Station 400 and scanned using an Agilent GeneArray Scanner.

The original microarray data generated by using MAS 5.0 software (Affymetrix) were globally normalized with a target signal of 500. Chips with a $<3$ fold resultant scale factor difference were included for data analysis. The dataset was divided into three subsets: bone, liver, and kidney, each with a pair of WT and SFX datasets. Using MAS
5.0 software, comparison analyses between WT and SFX subsets from different tissues were performed based on the Affymetrix change algorithm, in which Wilcoxon's signed rank test is used to compute $\mathrm{p}$-value of the change call, including Increase, Marginal Increase, No Change, Marginal Decrease, or Decrease. In addition, the intensity log ratio of SFX vs. WT was calculated for each probe set based on the Signal Log Ratio Algorithm. To identify differentially expressed genes between different groups, a cutoff value of twofold changes was chosen, based on most published studies (Schena et al., 1995; Gu et al., 2002b, 2003). To display distinct gene expression patterns and to find a possible gene interaction network based on gene expression pattern, hierarchical clustering was performed on three different data subsets using Cluster and TreeView software (Eisen et $a l ., 1998)$. To estimate the biological meaning of gene expression changes, Gene Ontology (GO) functional analysis was conducted, using the GenMAPP 2.0 software according to the instructions (http://www.genmapp.org).

\section{Semi-quantitative RT-PCR}

The expression levels of five genes determined by microarray analysis were confirmed by end-point RT-PCR. These genes were selected based on their potential roles in the development of abnormal skeletal phenotypes. Individual total RNA samples were separately subjected to the assay. Reverse transcription (RT) and PCR were conducted using the One-step RT-PCR kit (Invitrogen Inc, Carlsbad, $\mathrm{CA}$ ), as recommended by the manufacturer. Specific primers for selected genes are shown in Table 1. The reaction was performed in a total volume of $50 \mu \mathrm{L}$, at a final concentration of $4 \mathrm{ng} / \mu \mathrm{L}$ total RNA and $0.2 \mu \mathrm{M}$ sense and antisense primers. cDNA synthesis and pre-denaturation were performed in 1 cycle of $50{ }^{\circ} \mathrm{C}$ for $40 \mathrm{~min}$, and $94{ }^{\circ} \mathrm{C}$ for 2 min. PCR amplification was performed in 33 cycles of $94{ }^{\circ} \mathrm{C}$ for $30 \mathrm{~s}, 54-58{ }^{\circ} \mathrm{C}$ for $36 \mathrm{~s}$, and $72{ }^{\circ} \mathrm{C}$ for $2 \mathrm{~min}$. The PCR products were analyzed on a $2.0 \%$ agarose gel. Quantitative analysis of the PCR products was conducted using

Table 1 - Specific primers for semi-quantitative RT-PCR.

\begin{tabular}{|c|c|c|c|}
\hline Gene & & Sequence & Ps \\
\hline \multirow{2}{*}{ Mup $1 / 2$} & Forward & TGGTTGCTGACAAAACAGAA & \multirow{2}{*}{404} \\
\hline & Reverse & TGAGACAGGATGGAATGCAG & \\
\hline \multirow{2}{*}{ Mup3 } & Forward & CTCTATGGCCGAGAACCAGA & \multirow{2}{*}{404} \\
\hline & Reverse & ACGGGATTGCACTTCTCTGT & \\
\hline \multirow{2}{*}{ Rag1 } & Forward & CAGACCTCATTGCCAGGATT & \multirow{2}{*}{405} \\
\hline & Reverse & TCACAAAGTGTGCTGGGAAG & \\
\hline \multirow{2}{*}{$H p$} & Forward & TGGTGGATATCGGGCTAATC & \multirow{2}{*}{362} \\
\hline & Reverse & CATGTCATGAATGGCAAAGG & \\
\hline \multirow{2}{*}{ Pou2af1 } & Forward & GCCAGTGAAGGAGCTACTGAGAA & \multirow{2}{*}{364} \\
\hline & Reverse & GAGTGGTGGAGAAGCATAGGTCA & \\
\hline
\end{tabular}

Ps: Product size. 
Scion Image software (http://rsb.info.nih.gov/nih-image). The final RT-PCR signal was obtained by averaging 2 replicates for each sample.

\section{Results \\ Differential gene expression profiles in bone, liver and kidney}

According to the microarray measurements, the percentages of genes called present in the normal femur, liver and kidney, and in the $s f x$ femur, liver and kidney were $53.3 \%, 38.1 \%, 53.1 \%$, and $43.9 \%, 42.0 \%, 46.9 \%$, respectively. It is known that Gulo catalyzes the terminal step in vitamin C biosynthesis. Although Gulo is expressed exclusively in murine liver, vitamin $\mathrm{C}$ is required in various tissues. So, we expected to find different effects of a Gulo mutation on the gene expression in different tissues. Our data suggest that, in addition to the difference in phenotype, there were also differences in the gene expression profiles in the femur, kidney and liver between normal and $s f x$ mice (Table S1). Table 2 summarizes the gene expression changes in three different tissues from $s f x$ mice. Although bone fracture is the most obvious pathologic phenotype, the number of dysregulated genes in the femur was smaller $(\mathrm{n}=316)$ than in the liver $(\mathrm{n}=398)$ and kidneys $(\mathrm{n}=451)$.
Table 2 - Genes differ by more than a 2 -fold value between $s f x$ and normal control.

\begin{tabular}{lccc}
\hline Ratio of $s f x$ /normal signals & Bone & Liver & Kidney \\
\hline Range & 0.03 to 5.3 & 0.01 to 362.0 & 0.02 to 139.4 \\
$\leq 0.5$ & 226 & 200 & 155 \\
$>2$ & 90 & 198 & 296 \\
\hline
\end{tabular}

Interestingly, few common gene expression changes were identified among the different types of tissues. Only one gene (Cyp 51) was downregulated in all three tissues. There were 22 transcripts ( 7 upregulated, 15 downregulated) that showed similar changes between bone and liver, 12 (5 upregulated, 7 downregulated) between liver and kidney, and 7 ( 2 upregulated, 3 downregulated) between kidney and bone.

To display the distinct gene expression patterns of the murine femur, liver and kidney and to find clues of a gene interaction network based on the transcript level, Cluster and TreeView software was applied for hierarchical clustering. Examples of six main clusters with more than 10 genes are shown in \pm 1 . The biological meaning of these gene expression changes was further investigated by GO functional annotation (Table 3).

Table 3 - Gene Ontology biological profiling of different tissues in $s f x$ mice.

\begin{tabular}{|c|c|c|c|c|c|c|c|c|c|c|}
\hline Tissue-change & GOID $^{1}$ & GO name & $\begin{array}{l}\text { GO } \\
\text { type }\end{array}$ & $\begin{array}{l}\text { Number } \\
\text { changed }\end{array}$ & $\begin{array}{l}\text { Number } \\
\text { measured }\end{array}$ & $\begin{array}{c}\text { Number } \\
\text { in GO }\end{array}$ & $\begin{array}{l}\text { Percent } \\
\text { changed }\end{array}$ & $\begin{array}{l}\text { Percent } \\
\text { present }\end{array}$ & $\begin{array}{c}\mathrm{Z} \\
\text { score }\end{array}$ & $\begin{array}{c}\text { Permute } \\
\text { P }\end{array}$ \\
\hline \multirow[t]{7}{*}{ Bone-UP } & 9605 & response to external stimulus & $\mathrm{P}$ & 10 & 17 & 463 & 58.8 & 3.7 & 3.4 & 0.004 \\
\hline & 4871 & signal transducer activity & $\mathrm{F}$ & 15 & 32 & 2831 & 46.9 & 1.1 & 3.2 & 0.003 \\
\hline & 7165 & signal transduction & $\mathrm{P}$ & 16 & 36 & 2809 & 44.4 & 1.3 & 3.0 & 0.007 \\
\hline & 6952 & defense response & $\mathrm{P}$ & 12 & 25 & 559 & 48.0 & 4.5 & 2.9 & 0.003 \\
\hline & 6955 & immune response & $P$ & 11 & 23 & 481 & 47.8 & 4.8 & 2.7 & 0.010 \\
\hline & 9607 & response to biotic stimulus & $\mathrm{P}$ & 12 & 26 & 588 & 46.2 & 4.4 & 2.7 & 0.008 \\
\hline & 7154 & cell communication & $P$ & 21 & 60 & 3313 & 35.0 & 1.8 & 2.2 & 0.039 \\
\hline \multirow[t]{3}{*}{ Bone-DOWN } & 7399 & nervous system development & $\mathrm{P}$ & 13 & 13 & 370 & 100.0 & 3.5 & 2.1 & 0.035 \\
\hline & 48731 & system development & $\mathrm{P}$ & 13 & 13 & 398 & 100.0 & 3.3 & 2.1 & 0.035 \\
\hline & 9058 & biosynthesis & $P$ & 19 & 20 & 1201 & 95.0 & 1.7 & 2.1 & 0.053 \\
\hline \multirow[t]{2}{*}{ Liver-UP } & 5783 & endoplasmic reticulum & $\mathrm{C}$ & 20 & 29 & 443 & 69.0 & 6.5 & 2.3 & 0.026 \\
\hline & 48513 & organ development & $\mathrm{P}$ & 15 & 21 & 757 & 71.4 & 2.8 & 2.1 & 0.050 \\
\hline \multirow{4}{*}{ Liver-DOWN } & 16462 & pyrophosphatase activity & $\mathrm{F}$ & 13 & 17 & 447 & 76.5 & 3.8 & 2.1 & 0.051 \\
\hline & 17111 & nucleoside-triphosphatase activity & $\mathrm{F}$ & 13 & 17 & 422 & 76.5 & 4.0 & 2.1 & 0.051 \\
\hline & 5829 & cytosol & $\mathrm{C}$ & 13 & 16 & 237 & 81.3 & 6.8 & 2.4 & 0.013 \\
\hline & 16787 & hydrolase activity & $\mathrm{F}$ & 42 & 60 & 1866 & 70.0 & 3.2 & 3.1 & 0.002 \\
\hline \multirow[t]{7}{*}{ Kidney-UP } & 50789 & regulation of biological process & $P$ & 76 & 88 & 2665 & 86.4 & 3.3 & 4.7 & $<0.001$ \\
\hline & 50794 & regulation of cellular process & $\mathrm{P}$ & 71 & 82 & 2476 & 86.6 & 3.3 & 4.5 & $<0.001$ \\
\hline & 50791 & regulation of physiological process & $\mathrm{P}$ & 70 & 81 & 2425 & 86.4 & 3.3 & 4.4 & $<0.001$ \\
\hline & 51244 & $\begin{array}{l}\text { regulation of cellular physiological } \\
\text { process }\end{array}$ & $\mathrm{P}$ & 66 & 76 & 2351 & 86.8 & 3.2 & 4.4 & $<0.001$ \\
\hline & 5515 & protein binding & $\mathrm{F}$ & 90 & 113 & 3260 & 79.6 & 3.5 & 3.8 & $<0.001$ \\
\hline & 45449 & regulation of transcription & $\mathrm{P}$ & 35 & 39 & 1636 & 89.7 & 2.4 & 3.4 & 0.001 \\
\hline & 31323 & regulation of cellular metabolism & $\mathrm{P}$ & 38 & 43 & 1774 & 88.4 & 2.4 & 3.3 & 0.001 \\
\hline
\end{tabular}


Table 3 (cont.)

\begin{tabular}{|c|c|c|c|c|c|c|c|c|c|c|}
\hline Tissue-change & GOID $^{1}$ & GO name & $\begin{array}{l}\mathrm{GO} \\
\text { type }\end{array}$ & $\begin{array}{l}\text { Number } \\
\text { changed }\end{array}$ & $\begin{array}{l}\text { Number } \\
\text { measured }\end{array}$ & $\begin{array}{c}\text { Number } \\
\text { in GO }\end{array}$ & $\begin{array}{l}\text { Percent } \\
\text { changed }\end{array}$ & $\begin{array}{l}\text { Percent } \\
\text { present }\end{array}$ & $\begin{array}{c}\mathrm{Z} \\
\text { score }\end{array}$ & $\begin{array}{c}\text { Permute } \\
\text { P }\end{array}$ \\
\hline \multirow{5}{*}{ Kidney-DOWN } & 7165 & signal transduction & $\mathrm{P}$ & 49 & 58 & 2809 & 84.5 & 2.1 & 3.3 & 0.001 \\
\hline & 7154 & cell communication & $\mathrm{P}$ & 63 & 78 & 3313 & 80.8 & 2.4 & 3.2 & $<0.001$ \\
\hline & 9605 & response to external stimulus & $\mathrm{P}$ & 18 & 27 & 463 & 66.7 & 5.8 & 3.6 & $<0.001$ \\
\hline & 9607 & response to biotic stimulus & $\mathrm{P}$ & 22 & 36 & 588 & 61.1 & 6.1 & 3.4 & $<0.001$ \\
\hline & 6952 & defense response & $\mathrm{P}$ & 21 & 35 & 559 & 60.0 & 6.3 & 3.3 & 0.001 \\
\hline
\end{tabular}

${ }^{1}$ The detailed description of GO ID, GO type, number changed, number measured, number in GO, percent changed, percent present, Z score, and permute $P$ can be found on the website www.genmapp.org. The categories were selected based on $Z$ score $(\geq 2)$ and number changed $(>10)$. Redundant categories were disregarded.

\section{Gene expression profiling in femurs of sfx mice}

In this study, 316 transcripts were found to be differentially expressed in femurs from the $s f x$ mice. Many dysregulated genes in mutant femurs are involved in biosynthesis, response to external stimulus, signal transduction, and nervous system development (Table 3). Two major clusters are shown in Figure 1. The gene expression profile seems highly informative for osteoblasts, as the transcripts of several major genes known to be involved in the regulation of osteoblast differentiation and functions were found to be reduced in SFX mutant bones. These genes include distal-less homeobox 5 (Dlx5) (Sakaguchi and Melchers, 1986; Masuda et al., 2001), Twist 1 (Sadofsky, 2001; Brunner et al., 2003), member 1 of melanoma antigen family $\mathrm{D}$

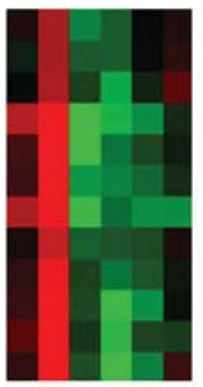

Cry1

$\mathrm{Bcl} 2$

Zfp125

EST (95184_f_at)

Ptpn22

Itgb2!

EST (95740_at)

Epb4.1

EST (98577_at)

EST (94027_at)

Sesn 1

X83313
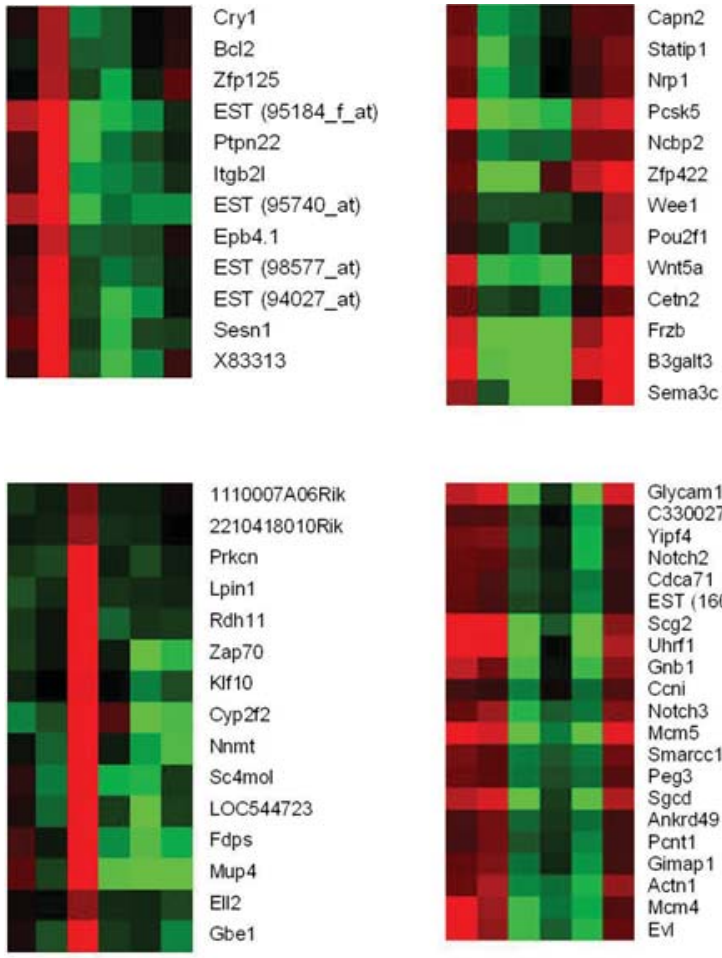

1110007A06Rik

2210418010Rik

Prken

Lpin1

Rdh11

Zap70

Klf 10

Cyp2f2

Nnmt

Sc4mol

LOC544723

Fdps

Mup4

EII2

Gbe1

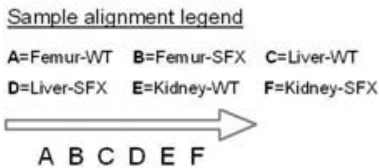

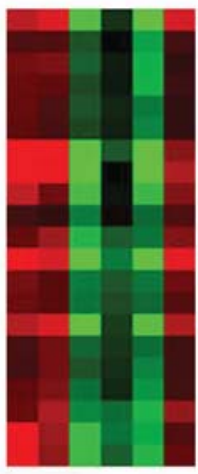

Glycam 1 C330027G06Rik Yipf4 Notch2 Cdca71 1

$\mathrm{Scg} 2$ $\mathrm{Scg} 2$
Uhrf1 Gnb1

Coni
Notch 3

Motch 3
Man5

Smarcc1

Peg3

Sgcd
Ankrd49

Pont1

Gimap1

Actn1

Mcm4

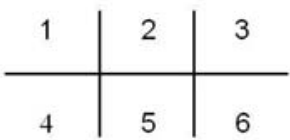

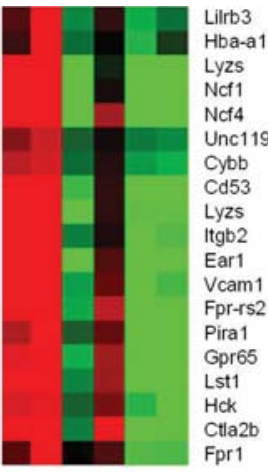

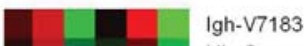

Ube2s

col6

Tspan33

LOC 434498

Fos

Hist1h1c

Tiparp

Srp19

Sipi

Rsad2

Xmr

SIfn4

Scgb1a1

Hapln1

Figure 1 - Hierarchical clustering results of dysregulated genes in the $s f x$ mice. One thousand and twenty eight differentially expressed genes with a fold change value of $\geq 2$ were chosen for hierarchical clustering, using the Cluster and TreeView software. Six major clusters with a correlation coefficient value of $\geq 0.9$ and more than 10 transcripts were identified in femur (clusters 1 and 2), liver (clusters 3 and 4), and kidney (clusters 5 and 6). Sample alignment legend is shown in the down-left corner. The probe-to-transcripts hybridization signal intensity in a microarray is indicated by color, from low (green) to high (red). A group of genes with the same or similar color indicates that they have the same or similar expression levels. The relative fold change for a transcript can be estimated based on the color scale in the down-right corner. 
(Maged1) (Ikeda et al., 1998), and v-ets avian erythroblastosis virus E26 oncogene homolog 1 (Ets1) (Uchio et al., 2004) (Table 4; most of them are not shown, because their values were less than the cutoff value of two fold change used in this study). Thus, this model may be helpful for identifying transcriptional regulators of osteoblast differentiation and bone formation.

Recombination-activating gene 1 (Rag1) was one of the most depressed genes in the diseased femurs, which was validated by RT-PCR (Table 5). Rag1 is critical for lymphocyte development. We also noticed that the expression of immunoglobulin lambda chain 5 (Igll1), which is selectively transcribed in pre-B lymphocytes (Sakaguchi and Melchers, 1986), was moderately decreased. These findings suggest a clue to the mechanisms explaining the role of vitamin $\mathrm{C}$ in the regulation of immunity.

\section{Gene expression profiling in liver of sfx mice}

Consistent with a previous report on the effect of ascorbic acid deficiency in the rat liver (Ikeda et al., 1998), we found that a panel of major urinary protein (Mup) genes, including Mup 1-5, was significantly suppressed in the $s f x$ mouse liver. The mouse Mups proteins are encoded by a family of about 35 to 40 highly conserved genes. They are expressed in a number of different secretory tissues of the mouse, including the mammary, parotid, sublingual, submaxillary and lachrymal glands, as well as in the liver (Shahan et al., 1987). Interestingly, we found a highly

Table 4 - Bone-specific gene expression in different tissues evaluated by microarray analysis.

\begin{tabular}{lccc}
\hline Tissue type & \multicolumn{3}{c}{ Gene $^{1}$} \\
\cline { 2 - 4 } & Dlx5 & Twist1 & Osteocalcin \\
\hline Bone & 0.56 & 0.63 & 0.14 \\
Liver & N/A & N/A & N/A \\
Kidney & N/A & N/A & N/A \\
\hline
\end{tabular}

${ }^{1}$ The value represents a ratio of SFX vs WT tissue signal intensity.

${ }^{2} \mathrm{~N} / \mathrm{A}$ indicates undetectable values using this method.

Table 5 - Comparison of some gene expressions in diseased femurs, measured by microarray and semi-quantitative RT-PCR.

\begin{tabular}{lcc}
\hline Gene & Array-based measurement $^{1}$ & PCR-based measurement \\
\hline Mup1/2 & 0.2 & 0.53 \\
Mup3 & 0.2 & 0.36 \\
Rag1 & 0.03 & $-\infty^{2}$ \\
Hp & 2 & 1.8 \\
Pou2af1 & 0.43 & 0.40 \\
Gapdh & & Internal control \\
\hline
\end{tabular}

${ }^{1}$ The value of measurement represents the ratio of SFX vs WT signal intensity.

${ }^{2}$ Undetectable in the diseased femurs. abundant expression of Mup 1/2 in the wild-type mouse femur. Moreover, a moderately decreased expression of Mup 1/2 and Mup 3 was found in the femurs of the sfx mice (Table 5). Since Mups are generally regarded as malepreferentially expressed genes, we validated our finding by RT-PCR using individual male and female mice (Figure 1). To our knowledge, this is the first time that non-gland tissue was found to express Mup genes in mammals.

\section{Gene expression profiling in kidney of sfx mice}

In the mutant kidney, the changes of gene expression were represented by decreased clusters 4-6 (Figure 2). It is clear that ascorbic acid deficiency exerts tissue-specific effects on gene expression. An increased expression of collagen synthesis genes such as Coll5al, Colla1, Colla2, Col4a4, Col4a5, Col6a1, and Col6a 3 mRNAs was found in the $s f x$ mouse kidney (Figure 3). Since enhanced collagen in renal fibroblasts is a major cause for renal fibrosis (Uchio et al., 2004), this finding suggests a mechanism for the role of ascorbic acid in the prevention of chronic renal diseases. In this study, the hepatic and renal cyclophilin $(C Y P)$ gene expression patterns in the $s f x$ mice showed downregulation of several CYPS that demonstrated tissue-preferential or abundant expression, including Cyp4a12 and Cyp $7 b 1$ in the kidney.

\section{RT-PCR confirmation of microarray data}

We realized that the small number of animals per group and sample pooling might have biased the overall results. To validate the sensitivity and accuracy of this study, five genes with different expression patterns across different tissues were selected for semi-quantitative RT-PCR confirmation, using RNAs from femur, liver and kidney. Particularly, Ragl was chosen because of its absence of ex-

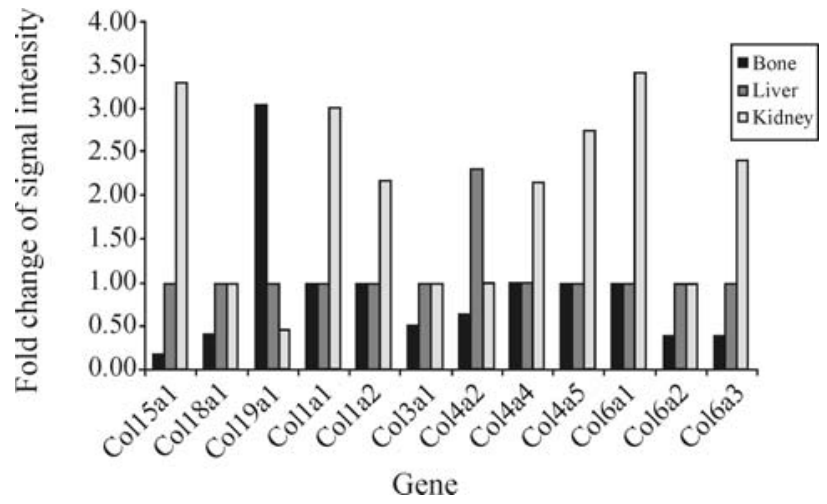

Figure 2 - Effects of ascorbic acid deficiency on collagen gene expression. Distinct effects of ascorbic acid deficiency on the expression of 12 subfamilies of collagen genes were observed in different tissues from mutant mice. The Y-bar indicates the ratio between the gene expression levels of $s f x$ and normal mice. The X-bar indicates genes in different tissues. Different tissue-specific collagen gene patterns were observed. Seven of them were upregulated in the kidney, and six were downregulated in the femurs from $s f x$ mice. Only one gene (Col4a2) was found to be upregulated. The expression of almost every gene in the femurs of $s f x$ mice was suppressed, while their expression levels were increased in the kidney. 

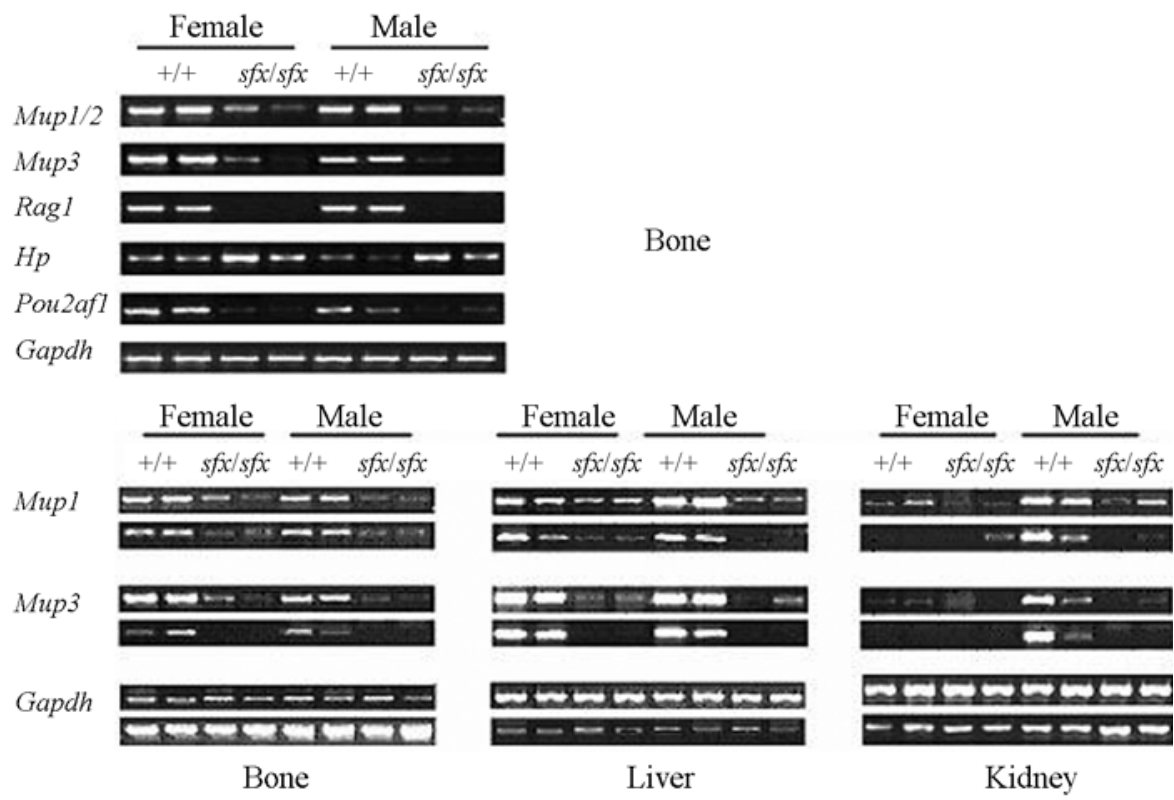

Figure 3 - Validation of microarray data using semi-quantitative RT-PCR. Five genes with different expression patterns across femur, liver and kidney, identified by microarray analysis, were selected for validating the microarray assay used, by semi-quantitative RT-PCR. Instead of using pooled samples, as in the microarray analysis, individual age-matched samples were used for the confirmation. The downregulation of Mup1/2, Mup3, Rag1, and Pou2af1 mRNAs, as well as the upregulation of $H p$ in the bone, were well validated in the $s f x$ mice (A, B). In addition, the gender specificity of Mup genes was identified, mainly in the wild-type murine kidney (B).

pression in the femurs of $s f x$ mice. Mup 1 and Mup 3 were chosen because of their gender expression specificity. The class 2 pou domain associating factor 1 (Pou2af1) was chosen for its significance in B cell response. Haptoglobin $(\mathrm{Hp})$ was chosen because of its high expression in the $s f x$ mice and in the rats lacking the Gulo gene (Ellender and Gazelakis, 1996; Ikeda et al., 1998). Their relation to Gulo deficiency ranges from well-documented to none reported, as will be discussed (in our) later on (see Discussion). As shown in Figure 3 and Table 5, most of the expression patterns of these genes were validated, except for genes Mup 1/2 and Mup3, for which microarray analysis showed an opposite change trend in the diseased kidney.

\section{Gender specificity of Mup1 and Mup3 genes in mouse kidney}

Gender specificity of Mup genes expression has been reported previously (Mucignat-Caretta et al., 1998). However, our initial analysis in femurs using RT-PCR (Figure $3 \mathrm{~A}$ ) indicated that the expression levels of Mupl/2 and Mup3 were similar between male and female mice in both normal and $s f x$ mice. Therefore, more RT-PCR assays were conducted, using RNAs from another panel of normal and diseased femurs, livers and kidneys. It turned out that gender specificity appeared mainly in the kidney, partially in the liver, but not in the femurs. As shown in Figure 3B, these two genes were highly expressed in the liver of male and female normal mice. However, in the kidney, they were only highly expressed in normal male mice. In the femur, their expressions showed a moderate level in both genders, compared to that in the liver and kidney. In $s f x$ mice, the expression of these two genes was suppressed in both males and females in all three tissues.

\section{Discussion}

This is a primary microarray study of the $s f x$ model, which we have recently confirmed to be a model of ascorbic acid deficiency (scurvy). Scurvy is typically characterized by a weakening of collagenous structures. The wellknown function of ascorbic acid is the synthesis of collagen through post-translational modification, by promoting the formation of hydroxyproline. Our results agree with previous reports about the impact of scurvy on major molecules, especially in bone. In this study, our data indicated a significant effect of ascorbic acid deficiency on the regulation of the expression of several major subfamilies of collagen genes in bone and kidney, with both fibril-forming and non-fibril-forming collagen genes being affected (Figure 2). Collagen plays an important role in building up the body structure, including the skin, bones, teeth, blood vessels, cartilage, tendons and ligaments. The downregulation of Col15a1, Col3a1, Col4a5, Col6a2, and Col6a3 may account for the reported poor bone formation.

While most of the array data need to be validated, we confirmed the expression levels of several important genes, which are worthy of future study. The effects of ascorbic acid deficiency on Mup gene expression suggest the possibility of ascorbic acid involvement in the transcriptional regulation of hormone metabolism. The precise role of altered Mups expression in the development of scurvy is un- 
clear. One of the well-documented functions of Mups is in chemical communication (Beynon and Hurst, 2003). The identification of Mup 1/2 expression in the femur provides a clue for their possible role in bone formation. Previously, Metcalf et al. (2000) demonstrated a reduced level of Mup expression in mice lacking a suppressor of cytokine signaling-2 (SOCS-2). SOCS members are considered negative regulators of cytokine receptor signaling via the Janus kinase/signal transducer and activation of transcription (STAT) pathway (the JAK/STAT pathway) (Yoshikawa et al., 2001). Interestingly, SOCS-2/- mice grow significantly more than normal mice, particularly regarding the length of their femurs and humeri (Metcalf et al., 2000). In the $s f x$ mouse, the length of the femurs and humeri is significantly reduced (Beamer et al., 2000). No abnormalities in bone architecture were evident in adult SOSC2 mice, while the $s f x$ mice have extremely fragile bones. Considering the negative effect of SOCS-2 on growth hormones (Turnley et al., 2002; Greenhalgh et al., 2005), Mup is potentially involved in the growth of skeletal tissues, especially the length of femurs and humeri, through the hormone metabolism. However, much work needs to be done to clarify the pathological significance of this unique change in the mouse with Gulo deficiency.

A previous study reveals that the hepatic $H p$ mRNA level is elevated in rats that are defective in ascorbic acid biosynthesis (Ikeda et al., 1998). Our data indicated that the expression level of $H p$ in the femur was slightly higher in the mutant mice. Since we had chosen a sample pooling approach, we thought that we might miss a lot of important genes with low-fold changes. So we did semi-quantitative RT-PCR to evaluate the expression status of $H p$ in these three tissues. Interestingly, we did confirm the upregulation of $H p$ in the femur. It has been recently reported that IL-6 induced the expression of the $H p$ and the suppression of the Mup gene in mice (Gervois et al., 2004). The upregulation of $\mathrm{Hp}$ and downregulation of Mup in the femur of the Gulo deficiency mouse raise the interesting question of whether they are functionally connected in the same pathway that is regulated by Gulo in the bone or skeletal development.

Since Rag1 plays an essential role in the diversity of cellular and humoral immunity (Sadofsky, 2001), the suppressed expression of Ragl may be related to the decrease of $I g l-5$. By checking more evidence for dysregulated B cell development, we found that Pou2af1, which plays an important role in B cell development and function (Brunner $e t$ al., 2003), was slightly decreased in the $s f x$ mouse femurs. Importantly, this finding was well confirmed by semiquantitative RT-PCR (Figure 3, Table 5). This finding raises the possibility of ascorbic acid playing a role in the regulation of B lymphocyte development and functions.

Microarray analysis, however, could not distinguish between gene changes caused by the Gulo defect and changes resulting from the organism reacting to the $s f x$ disease state. Many down- or upregulated genes identified in this study may be important for the physiology and pathology of bone, liver or kidney. However, further study is needed to clarify their exact role in the development of those organs. In the comparison of gene expression profiles in femurs, we were unable to wash away the bone marrow, because the bones of $s f x$ mice are extremely fragile. Instead, we extracted RNA from whole bones. We feel that our approach likely probes the real biological events in the femur. An alternative way is using cultured osteoblasts, however, we are almost certain that the biology in cultured cells will differ from that of bone tissues. In this case, femur tissues and cultured cells each have their advantage and disadvantage. Furthermore, our previous study indicated that $s f x$ mice nearly have no osteoblasts in their femurs (Beamer et al., 2000). Therefore, we feel confident that this study provides useful information on the $s f x$ mouse.

\section{Acknowledgments}

Supported funding for WKG comes from the Center of Excellence for Genomics and Bioinformatics, Center of Excellence for Diseases of Connective Tissues at the University of Tennessee Health Science Center, and the Veterans Administration Medical Center, Memphis, TN; and from NIH (AR51190). Funding for WGB is from NIH AR43618 (WGB) and CA43619 (CORE grant, The Jackson Laboratory).

\section{References}

Beamer WG, Rosen CJ, Bronson RT, Gu W-K, Donahue LR, Baylink DJ, Richardson CC, Crawford GC and Barker JE (2000) Spontaneous fracture $(s f x)$ : A mouse genetic model of defective peripubertal bone formation. Bone 27:619-626.

Beynon RJ and Hurst JL (2003) Multiple roles of major urinary proteins in the house mouse, Mus domesticus. Biochem Soc Trans, Part 1:142-146.

Brunner C, Laumen H, Nielsen PJ, Kraut N and Wirth T (2003) Expression of the aldehyde dehydrogenase 2-like gene is controlled by BOB.1/OBF.1 in B lymphocytes. J Biol Chem 278:45231-45239.

Eisen MB, Spellman PT, Brown PO and and Botstein D. (1998) Cluster analysis and display of genome-wide expression patterns. Proc Natl Acad Sci USA 95:14863-14868.

Ellender G and Gazelakis T (1996) Growth and bone remodeling in a scorbutic rat model. Aust Dent J 41:97-106.

Gervois P, Kleemann R, Pilon A, Percevault F, Koenig W, Staels B and Kooistra T (2004) Global suppression of IL-6-induced acute phase response gene expression after chronic in vivo treatment with the peroxisome proliferator-activated receptor-alpha activator fenofibrate. J Biol Chem 279:1615416160.

Greenhalgh CJ, Rico-Bautista E, Lorentzon M, Thaus AL, Morgan PO, Willson TA, Zervoudakis P, Metcalf D, Street I, Nicola NA, Nash AD, Fabri LJ, Norstedt G, Ohlsson C, Flores-Morales A, Alexander WS and Hilton DJ (2005) SOCS2 negatively regulates growth hormone action in vitro and in vivo. J Cli. Inves 115:397-406. 
Gu W, Li XM, Edderkaoui B, Strong DD, Lau KH, Beamer WG, Donahue LR, Mohan S and Baylink DJ (2002a) Construction of a BAC contig for a $3 \mathrm{cM}$ biologically significant region of mouse chromosome 1. Genetica 114:1-9.

Gu W, Li X, Lau KH, Edderkaoui B, Donahue LR, Rosen CJ, Beamer WG, Shultz KL, Srivastava A, Mohan S and Baylink DJ (2002b) Gene expression between a congenic strain that contains a quantitative trait locus of high bone density from CAST/EiJ and its wild-type strain C57BL/6J. Funct Integr Genomics 1:375-386.

Gu W, Li X-M, Roe BA, Lau K-H, Edderkaoui B, Mohan S and Baylink DJ (2003). Application of genomic resources and gene expression profiles to identify genes that regulate bone density. Current Genomics 4:75-102.

Ikeda S, Horio F and Kakinuma A (1998) Ascorbic acid deficiency changes hepatic gene expression of acute phase proteins in scurvy-prone ODS rats. J Nutr128:832-838.

Jiao Y, Li X, Beamer WG, Yan J, Tong Y, Goldowitz D, Roe B and $\mathrm{Gu}$ W (2005) A deletion causing spontaneous fracture identified from a candidate region of mouse chromosome 14. Mamm Genome 16:20-31.

Masuda Y, Sasaki A, Shibuya H, Ueno N, Ikeda K and Watanabe $\mathrm{K}$ (2001) Dlxin-1, a novel protein that binds Dlx5 and regulates its transcriptional function. J Biol Chem 276:53315338.

Metcalf D, Greenhalgh CJ, Viney E, Willson TA, Starr R, Nicola NA, Hilton DJ and Alexander WS (2000) Gigantism in mice lacking suppressor of cytokine signalling-2. Nature 405:1069-1073.

Mucignat-Caretta C, Caretta A and Baldini E (1998) Proteinbound male urinary pheromones: Differential responses according to age and gender. Chem Senses 23:67-70.
Sadofsky MJ (2001) The RAG proteins in V(D)J recombination: More than just a nuclease. Nucleic Acids Res 29:1399-409.

Sakaguchi N and Melchers F (1986) Lambda 5, a new lightchain-related locus selectively expressed in pre-B lymphocytes. Nature 324:579-82.

Schena M, Shalon D, Davis RW and Brown PO (1995) Quantitative monitoring of gene expression patterns with a complementary DNA microarray. Science 270:467-470.

Shahan K, Denaro M, Gilmartin M, Shi Y and Derman E (1987) Expression of six mouse major urinary protein genes in the mammary, parotid, sublingual, submaxillary, and lachrymal glands and in the liver. Mol Cell Biol 7:1947-54.

Turnley AM, Faux CH, Rietze RL, Coonan JR and Bartlett PF (2002) Suppressor of cytokine signaling 2 regulates neuronal differentiation by inhibiting growth hormone signaling. Nat Neurosci 5:1155-1162.

Uchio K, Manabe N, Yamaguchi-Yamada M, Goto Y, Yamamoto Y, Ogura A and Miyamoto H (2004) Changes in the localization of type I, III and IV collagen mRNAs in the kidneys of hereditary nephritic (ICGN) mice with renal fibrosis. J Vet Med Sci 66:123-8.

Yoshikawa H, Matsubara K, Qian G.-S, Jackson P, Groopman JD, Manning JE, Harris CC and Herman JG (2001) SOCS-1, a negative regulator of the JAK/STAT pathway, is silenced by methylation in human hepatocellular carcinoma and shows growth-suppression activity. Nature Genet 28:29-35.

\section{Supplementary Material}

- Table S1

This material is available as part of the online article from http://www.scielo.br/gmb

Associate Editor: Emmanuel Dias Neto 